\title{
Reconstruction of the chin using an expanded deltopectoral flap following multiple recurrences of oral cancer
}

\author{
Chenicheri Balakrishnan MD, David Hackenson MD, Anila Balakrishnan BS, David Elliott BS, Daniel Careaga MD
}

C Balakrishnan, D Hackenson, A Balakrishnan, D Elliott, D Careaga. Reconstruction of the chin using an expanded deltopectoral flap following multiple recurrences of oral cancer. Can J Plast Surg 2012;20(3):e37-e39.

An important alternative to free tissue transfer in patients requiring correction of soft tissue chin defects are local and regional flaps, such as the pectoralis major myocutaneous flap and deltopectoral flap. With predictable vascular supply, potential for large size, and good aesthetic match for facial and cervical skin, the deltopectoral flap can offer the reconstructive surgeon additional options in patients who lack vessels suitable for free tissue transfer. The use of an expanded deltopectoral flap for a staged reconstruction of the chin in a patient with cancer recurrences, concomitant resections, radiation and multiple reconstructions is reported.

Key Words: Chin reconstruction; Deltopectoral

$\mathrm{R}$ econstruction of the chin following tumour resection or trauma is a challenging problem due to the complex anatomical structure and prominent aesthetic role of the chin. In patients requiring only soft tissue reconstruction, there are many local and free tissue transfers that can be used. Unfortunately, there is a population of patients in whom the recipient vessels may be inadequate, including those who have undergone multiple resections for tumour recurrence or have received radiation as part of their treatment regimen. A lack of suitable proximate vessels in these patients complicates the use of free flaps and, in this case, regional flaps may offer a technically and aesthetically acceptable solution. Before the development of microvascular anastomosis and the free tissue transfer, the deltopectoral flap was frequently used for facial reconstruction. While free tissue transfers have overtaken the use of regional flaps in facial reconstruction, regional flaps hold great potential. We report the use of an expanded deltopectoral flap for reconstruction of the chin following multiple surgeries associated with three recurrences of squamous cell carcinoma of the oral cavity.

\section{CASE PRESENTATION}

A 59-year-old man presented with a request for chin reconstruction. He had a significant history of head and neck cancer. At 48 years of age, he underwent a partial laryngectomy with left-sided modified lymphadenectomy and radiation. Three years later, he developed floor of mouth cancer that was resected along with a partial glossectomy and a right-sided neck dissection. The defect was reconstructed with a free radial forearm flap. His metastatic workup was negative at that time. One year later, he presented with severe pain in his jaw with induration of the chin and lower lip and was noted to have a pathological fracture of the mandible. This was resected and reconstructed with a vascularized osteocutaneous fibular flap and followed by chemotherapy. He developed an orocutaneous fistula on the right side approximately one year later, which was repaired with a right pectoralis major myocutaneous flap after resection. He required another course of

\section{Une reconstruction du menton à l'aide d'un lambeau deltopectoral élargi après de multiples récurrences d'un cancer de la bouche}

Les lambeaux locaux et régionaux, tels que le lambeau myocutané du grand pectoral et le lambeau deltopectoral, constituent une solution de rechange importante au transfert de tissus libres chez les patients qui ont besoin de faire corriger des anomalies des tissus mous du menton. Étant donné son alimentation vasculaire prévisible, sa grande dimension potentielle et sa correspondance esthétique avec la peau du visage et du cou, le lambeau deltopectoral peut offrir au chirurgien en reconstruction des possibilités supplémentaires auprès des patients dont les vaisseaux ne conviennent pas au transfert de tissus libres. Les auteurs décrivent le recours à un lambeau deltopectoralé largi dans le cadre d'une reconstruction graduelle du menton chez un patient subissant des récurrences de cancer, des résections concomitantes, une radiation et des reconstructions multiples.

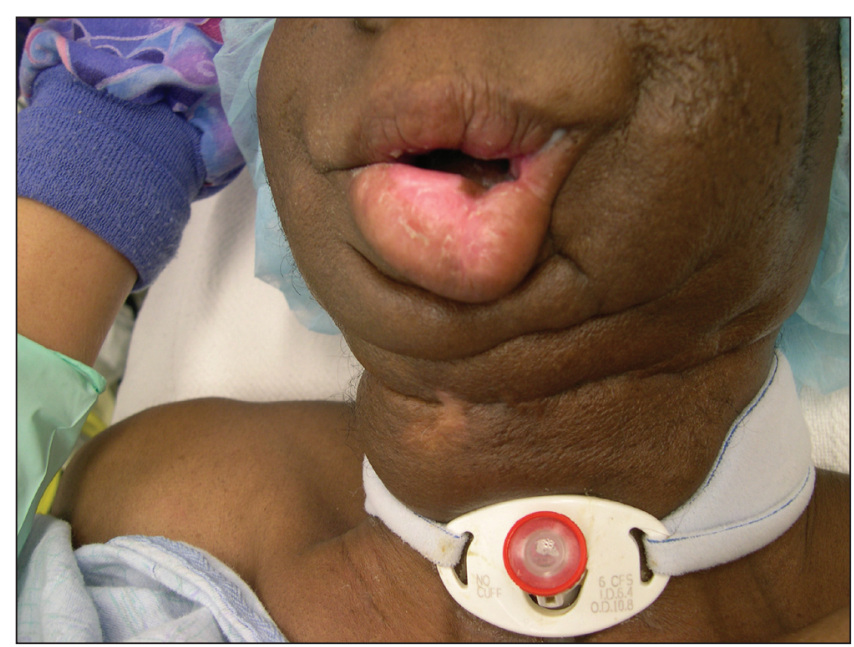

Figure 1) Loss of chin after multiple resection

chemotherapy because there was recurrence in the specimen. He had been disease free for five years.

Due to the multiple surgeries and radiation, he experienced significant scarring of the neck (Figure 1). A free tissue transfer was not feasible given the lack of suitable recipient vessels in his neck; therefore, a decision was made to undertake staged reconstruction of his chin using a deltopectoral flap. A tissue expander was placed so that the donor site could be closed following elevation of the flap (Figure 2). After three weeks of expansion, the flap was tubed and transferred to the chin (Figure 3). The flap was detached from the chest and transferred to the left angle of the jaw after three weeks (Figure 4). Revision of the flap was performed at three months (Figures 5 and 6) to achieve acceptable appearance of the chin (Figure 7). 


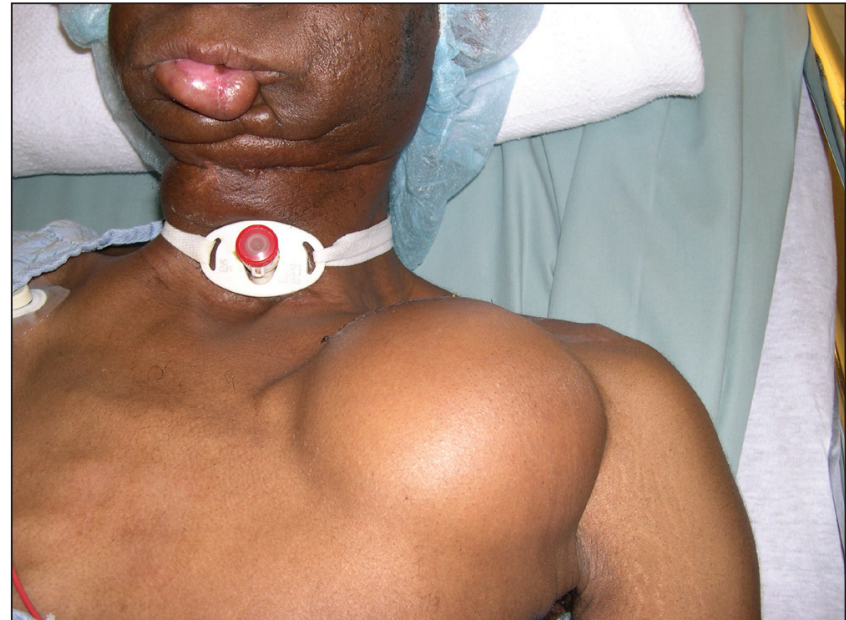

Figure 2) Tissue expansion of the deltopectoral flap

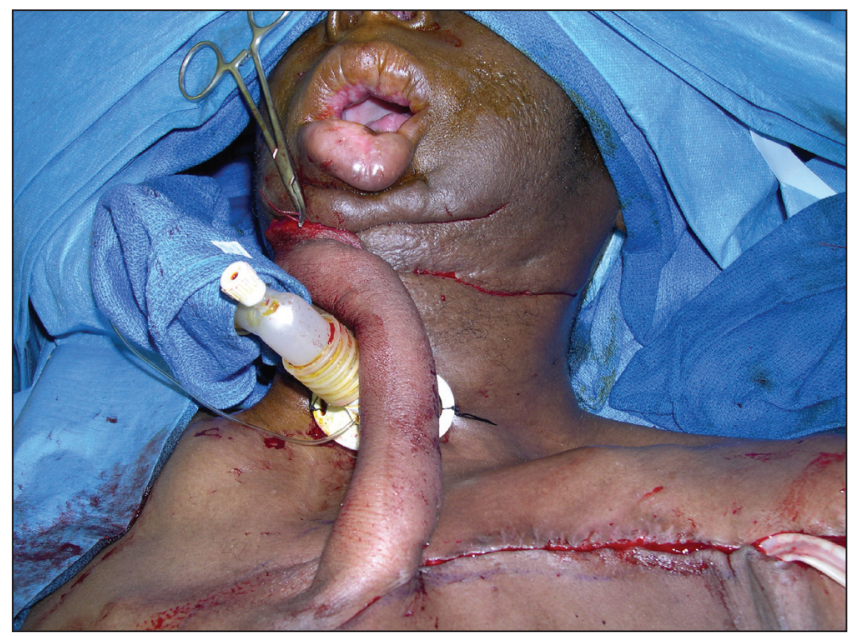

Figure 3) Tubed flap transferred to chin

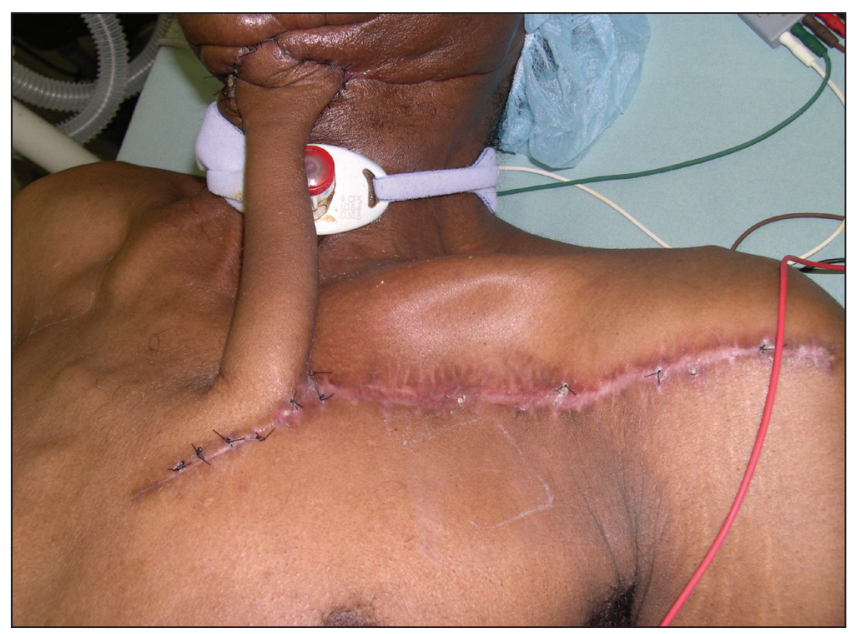

Figure 4) Division of flap and transposed

\section{DISCUSSION}

This type of patient presents a significant challenge to the reconstructive surgeon, but also highlights one of the rewards of the field - the ability to choose among many available reconstructive options. Since the development and maturation of the microvascular free tissue transfer in the 1960s and 1970s, free flaps have supplanted most other techniques in reconstructive plastic surgery (1). If one always takes the

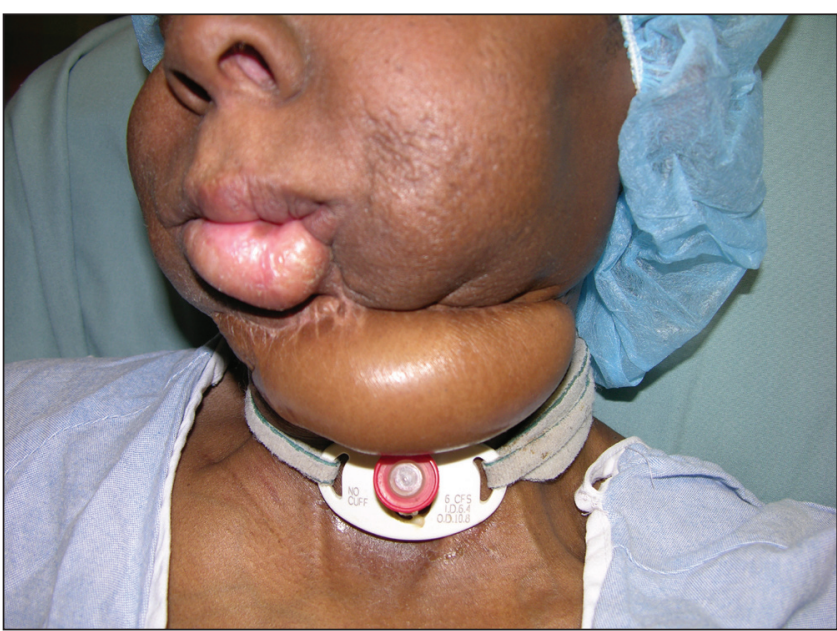

Figure 5) Revision of the flap

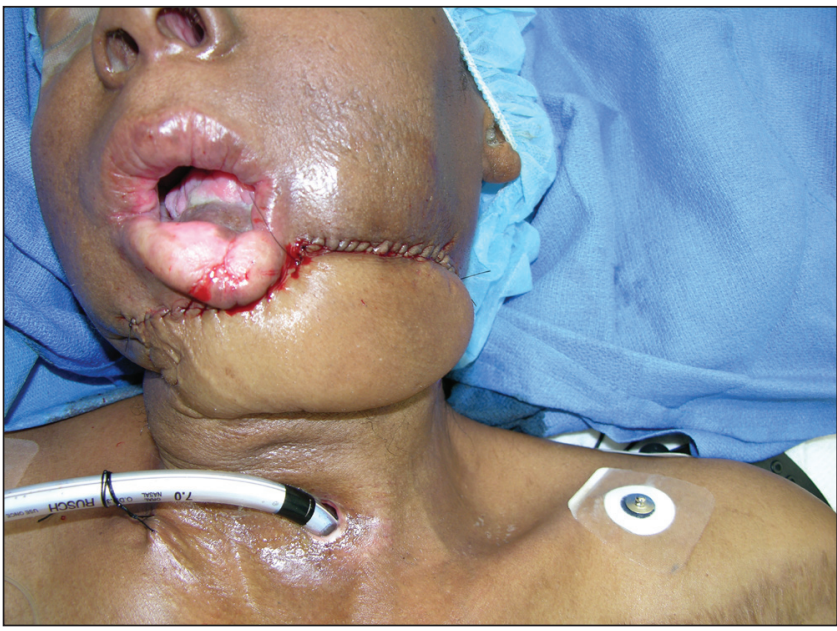

Figure 6) Revision of the flap

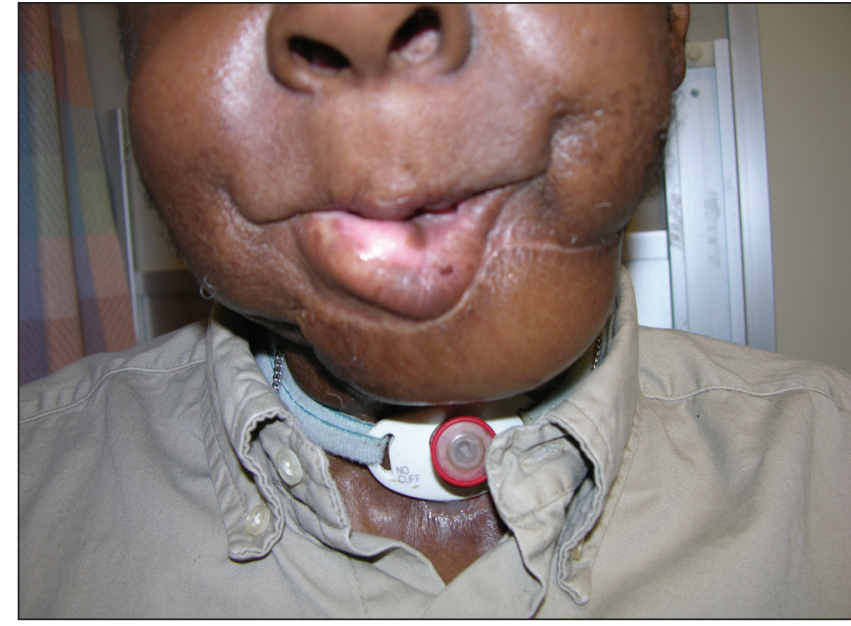

Figure 7) Final result

reconstructive elevator to free flaps to reconstruct head and neck defects, what is available when free tissue transfer is not an option? $(2,3)$.

Due to the reliance on free flap reconstructions, local and regional flaps are not commonly used because there are some patients in whom free flaps are not appropriate, despite the many attempts to modify free flap implementation, including venous loops and flow-through flap 
anastomosis (4) and distant or unconventional anastomotic sites (5). There are many alternatives to free flaps that offer technically and aesthetically appealing results in multiple stages. As evidence of the wide range of possibilities, the latest edition of Grabb's Encyclopedia of Flaps (6) lists 50 different options for neck and cheek reconstruction.

Among those is the deltopectoral flap, a versatile flap with many potential benefits and few drawbacks when used appropriately. The deltopectoral flap originated in the beginning of the 20th century. Although the modern implementation is attributed to Bakamjian (7), the first description was reported by Aymard (8) in 1917, a contemporary of and sometimes rival to Gillies (9). The deltopectoral flap is a parasternal, axial fasciocutaneous flap based on the perforators of the internal mammary artery. At its fullest extent, it can reach practically all of the lower two-thirds of the face. This flap has been used for nasal reconstruction (9) pharyngoesophageal reconstruction (7), fistula closure (10), tracheal reconstruction (11), full-thickness vascularized skin repair, as cover for critical head and neck structures, and as cover for other flaps (12). Use of the deltopectoral flap as a free fasciocutaneous flap has been reported (13).

The deltopectoral flap is particularly useful in patients requiring coverage of the anterior or lateral neck, and provides an excellent match for colour, texture, thickness and hair-bearing to facial skin. Because the flap typically lies outside of the radiated and operative fields for head and neck cancers, it remains a source of vascularized tissue $(14,15)$ even after multiple previous interventions. When compared with the pectoralis major myocutaneous flap, the deltopectoral flap has little or no effect on shoulder function and, for female patients, it produces less distortion of breast tissue. The donor site can be closed primarily in many circumstances, especially when prepared with a tissue expander. The donor site also presents less morbidity than a comparable pectoralis flap or a radial flap $(16,17)$. Finally, the deltopectoral flap can be elevated and transposed without repositioning the patient, allowing the donor and recipient sites to be prepared simultaneously (18).

\section{REFERENCES}

1. Dunn R, Watson S. Why climb a ladder when you can take the elevator? Plast Reconstr Surg 2001;107:283.

2. Bennett N, Choudary S. Why climb a ladder when you can take the elevator? Plast Reconstr Surg 2000;105:2266-7.

3. Gottlieb LJ, Krieger LM. From the reconstructive ladder to the reconstructive elevator. Plast Reconstr Surg 1994;93:1503.

4. Cuelemans P, Hofer SO. Flow through anterolateral thigh flap for a free osteocutaneous fibula flap in secondary composite mandible reconstruction. Br J Plast Surg 2004;57:358-61.

5. Urken ML, Higgins KM, Lee B, Vickery C. Internal mammary artery and vein: Recipient vessels for free tissue transfer to the head and neck in the vessel-depleted neck. Head Neck 2006;28:797-801.

6. Strauch B, Vasconez L, Hall-Findlay E, Lee B, eds. Grabb's Encyclopedia of Flaps, 3rd edn. Philadelphia: Lippincott, Williams, and Wilkins, 2009.

7. Bakamjian, VY. A two-stage method for pharyngeoesophageal reconstruction with primary pectoral skin flap. Plast Reconstr Surg $1965 ; 36: 173-84$.

8. Aymard J. Nasal reconstruction. Lancet 1917;2:888-91.

9. Santoni-Rugiu P, Sykes PJ. A History of Plastic Surgery. London: Springer, 2007.

10. Balakrishnan C, Narasimhan K, Gursel T, Jackson O, Schaffner A. Closure of orocutaneous fistula using a pedicled expanded deltopectoral flap. Can J Plast Surg 2008;16:178-80.

11. Kumaran S, Nambi GI, Paul MK, Gupta AK. Post electrical burn tracheal defect reconstruction with pre-fabricated deltopectoral flap - a case report. J Plast, Reconstruct Aesthetic Surg, 2009;62:e93-4.

12. Andrews BT, McCulloch TM, Funk GF, Graham SM, Hoffman HT. Deltopectoral flap revisted in the microvascular era: A single-
The deltopectoral flap often requires multiple surgeries to achieve optimum results (16). This is particularly relevant for a 'walking' flap, which may require several surgeries spaced out over months (12). Many authors have reported flap success rates in the range of $75 \%$ to $90 \%$, with failures typically including distal flap necrosis $(12,16,19,20)$. With meticulous flap handling and careful attention to the fascial plane during dissection, the deltopectoral flap has the potential for rates of success of $90 \%$ to $95 \%$, comparable with those of free flaps (16). One suggestion is to avoid tubing the pedicle base, thereby removing potential limitation on blood flow in the event of postoperative swelling $(15,20)$. Feng et al (15) reported 34 cases using the extended deltopectoral flap with no flap loss, and in which only two cases required local advancement of skin or skin grafting to complete the closure, yielding a success rate $>94 \%$. Another technique, the 'delayed flap', involves undermining portions of the flap without moving it from the donor bed. Theoretically, this promotes vascular reorganization in the distal extent of the flap overlying the deltoid, which should improve survival. In practice, it has yielded somewhat mixed results, ranging from $84 \%$ to $100 \%$ success $(12,20)$. In a large review of 678 deltopectoral flaps, 125 of which were delayed, Gilas et al (20) concluded that delay did not yield a significant change in rate of complications or major necrosis when compared with a regular dissection. Hence the 'delay' operation seems inadvisable, especially because the delay step is itself associated with flap necrosis in a small number of cases.

Due to the use of free tissue transfer as the primary reconstructive option, the deltopectoral flap is used most commonly as a salvage operation. Although the donor site morbidity associated with the use of a deltopectoral flap is high, it can be reduced with expansion of the area in elective cases. The present case demonstrated the utility and versatility of the deltopectoral flap in reconstructing the chin beyond salvage.

institution 10-year experience. Ann Otol Rhinol Laryngol 2006;115:35-40.

13. Sasaki K, Nozaki M, Honda T, Morioka K, Kikuchi Y, Huang T. Deltopectoral skin flap as a free skin flap revisited: Further refinement in flap design, fabrication, and clinical usage. Plast Reconstr Surg 2001;107:1134-41.

14. Bianchi B, Ferri A, Ferrari S, Copelli C, Poli T, Sesenna E. Free and locoregional flap associations in the reconstruction of extensive head and neck defects. Int J Oral Maxillofacial Surg 2008;37:723-9.

15. Feng GM, Cigna E, Lai HK, et al. Deltopectoral flap revisited: Role of the extended flap in reconstruction of the head and neck. Scand J Plast Reconstr Surg Hand Surg 2006;40:275-80.

16. Chen CH, Lin GT, Fu YC, et al. Comparison of delopectoralis flap and free radial forearm flap in reconstruction after oral cancer ablation. Oral Oncol 2005;41:602-6.

17. Bey E, Hautier A, Pradier JP, Duhamel P. Is the deltopectoral flap born again? Role in post-burn head and neck reconstruction. Burn 2009;35:123-9.

18. Blackwell KE, Buchbinder D, Biller HF, Urken ML. Reconstruction of massive defects in the head and neck: The role of simultaneous distant and regional flaps. Head and Neck 1997:620-8.

19. Sertorio CB, Dedivitis RA. Deltopectoral flap for reconstruction after head and neck cancer resections. Plast Reconstr Surg 2006;117:1055-6.

20. Gilas T, Sako K, Razack MS, Bakamjian VY, Shedd DP, Calamel PM. Major head and neck reconstruction using the deltopectoral flap - a 20 year experience. Am J Surg 1986;152:430-4. 